\title{
The Release of Doxorubicin's Active Ingredient from the Hydrogels with Poly (HEMA/Acrylamide/ Itaconic acid) and Their Biological Function
}

\author{
Ishak Afşin Kariper \\ Department of Science Education. Erciyes University, Education Faculty Primary Education, KAYSERI.
}

\begin{abstract}
In this study, Poly (HEMA/Acrylamide/ Itaconic acid) (HAl) polymer was synthesized for using in the release of Doxorubicin drug. Poly (HEMA/acrylamide/ltaconic acid) (HAl) hydrogel was prepared by a radical addition reaction in aqueous media formed by HEMA, acrylamide, Itaconic acid, in the presence of TEMED ( $N, N, N^{\prime}, N^{\prime}$-tetramethylenediamine). The characterization of the polymer was performed by FTIR analysis. At the same time, swelling and drug absorption capabilities of the polymers were analyzed. It has been observed that the entire drug, which was added to the solution with $0.1 \mathrm{mg}$ of polymer, was absorbed in around 25 hours. This measurement showed that the absorption of this polymer is quite high compared to many polymers in the literature. Moreover, this polymer showed $80 \%$ swelling at 1000 minutes. In the light of these results, it has been concluded that this new polymer is very suitable for the release of Doxorubicin drug.
\end{abstract}

Key words: Doxorubicin, Poly (HEMA/acrylamide/Itaconic acid), Drug release, FTIR, kinetix

\section{INTRODUCTION}

Drug-polymer interactions are accepted as the first step of the controlled release, where the polymeric structure, in which active ingredient is adsorbed, is as important as the active ingredient of the drug. Synthesized polymers should not interact with the active ingredient, should be biocompatible and biodegradable, should be produced easily and cost effectively. Network structures that are swellable in water are called as hydrogels. Hydrogels are quite useful on controlled drug release systems because they respond the changes on $\mathrm{pH}$, temperature, ionic concentration; they have swelling capability; and they control the diffusion of drug molecules. With the macro pores that they have, they show fast swelling kinetics.

Doxorubicin is an anti-cancer agent that is frequently used in the research and development of drug carrying systems. Doxorubi- cin, which is a derivative of anthracycline, makes intercalation into DNA as all other anthracycline. The full action mechanism of doxorubicin is complex and not fully understood yet, however it is guessed that it interacts with DNA through intercalation. ${ }^{1}$ It is known that doxorubicin interacts by intercalation and prevents its biosynthesis. ${ }^{2}$ If doxorubicin is present in the media, the advancement of Topoisomerase II enzyme, which allows the opening of DNA, is prevented. During the replication of DNA, doxorubicin stabilizes the topoisomerase-DNA complex that is formed after the cut of DNA by topoisomerase and prevents the reunion of DNA double helix, thus it stops the replication of the DNA., ${ }^{3,4}$ Combined treatment trials performed using Sirolimus (rapamycin) and doxorubicin was promising in healing Akt-positive lymphomas of mice. ${ }^{5}$ Doxorubicin is also used in HIV treatment. The immuno-composite that
Submission Date: 04-01-2017; Revision Date: 18-03-2017; Accepted Date: 30-03-2017

DOI: 10.5530/ijper.51.3.67 Correspondence: I. Afşin Kariper, Department of Science Education, Erciyes University, Education Faculty Primary Education, KAYSERI Phone: +905055204871 E-mail: akariper@gmail.com

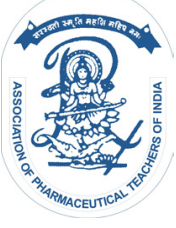

www.ijper.org 
was obtained by binding doxorubicin to a monoclonal mouse antibody could eliminate HIV infection in mice. Antiretroviral treatment (ART) still leaves some amount of HIV in the host body. The immuno-composite containing doxorubicin has the potential of being a complementary treatment for destroying cells that continue to express antigen. ${ }^{6}$ But, doxorubicin was seen to be more effective in the soft tissues and in breast cancer.

Acrylamide can usually join radical reactions with its carbon-carbon double bonds, thus it is a chemical that is widely seen in the structure of the polymers that were synthesized for drug absorption and release. In fact, it has been found that it is formed as a result of heat treatment from foods rich in starch, after which the studies on its residues remaining in the body are increasing. The formation of acrylamide is observed on many foods rich in protein. There are many studies aiming to remove / decrease if from the product because it is considered as a potential carcinogen. Therefore, even though the synthesized polymer was carefully purified, cytotoxicity tests were performed for acrylamide.

On the other hand, the risks of HEMA, which is easily polymerized as acrylamide, to human health are not know, thus cytotoxicity tests gained more importance. HEMA has the $\mathrm{H}_{2} \mathrm{C}=\mathrm{CCH}_{3} \mathrm{COOCH}_{2} \mathrm{CH}_{2} \mathrm{OH}$ formulas and similar to acrylamide it can easily join polymerization through double bonds. Itaconic acid is a white, crystal chemical, with formulas $\mathrm{C}_{5} \mathrm{H}_{6} \mathrm{O}_{4}$. In addition, it is a chemical whose in vitro effect against bacteria was proven.

This study aims to perform the interaction of Poly (HEMA/Acrylamide/ Itaconic acid) (HAI) polymer with doxorubicin's active ingredients, which is used as an anti-cancer agent, and examine its absorption capability and cytotoxic impact of the polymers.

\section{MATERIALS AND METHODS}

\section{Synthesis of HAI Polymer}

Poly (HEMA/acrylamide/ Itaconic acid) (HAI) polymer was prepared by a radical addition reaction. 5 mmol HEMA, $3 \mathrm{mmol}$ acrylamide, and 1, $5 \mathrm{mmol}$ Itaconic acid were dissolved in water. $0,1 \mathrm{mmol}$ EGDMA (Ethylene glycol dimetakrilat) was added as cross binder, 0,02 mmol APS (ammoniumpersulphate) was added for starting polymerization and 0,06 mmol TEMED (N,N,N',N'-tetramethylenediamine) was added as accelerator, mixed for 1 minute and filled into pipets; they were hold at $22^{\circ} \mathrm{C}$ for 24 hours. Then polymers were removed from pipets, cut in pieces of 3-4 mm, washed with double distilled water and dried first in air, than in the vacuum incubator.

\section{Characterization of HAI Polymer}

Structural characterization of HAI polymer was performed through swelling experiments and Fourier Transform Infrared (FTIR).

Cytotoxicity

\section{Cultivation of the Cells}

Cell cultivation studies should provide appropriate conditions and required medium for the existence and multiplication of the cells in vitro environment. Inactive serum should be definitely added to the medium for fulfilling the needs of the cells and acting as a buffer. The medium environment that we have used in our study was DMEM medium consisting of $10 \%$ Fetal bovine serum (FBS), 1\% L-glutamine, $100 \mathrm{IU} / \mathrm{mL}$ penicillin and $10 \mathrm{mg} / \mathrm{mL}$ streptomycin. Cancer cell lines that were produced in DMEM medium were multiplied in the incubator at $37^{\circ} \mathrm{C}$, with $95 \%$ humidity and $5 \% \mathrm{CO}_{2}$. Cytotoxicity tests were performed on Mouse Fibroblast Cell Lines (L929) through XTT Test, where L929 have been procured from ATTC.

Cytotoxicity Tests

\section{Determination of Composites' IC $_{50}$ dosage for Cancer Cell Lines}

$\mathrm{IC}_{50}$ dosage indicates the inhibitor's concentration required to kill $50 \%$ of the target. $\mathrm{IC}_{50}$ dosage of the composites have been determined by XTT (2, 3-bis (2-methoxy-4-nitro-5-sulfophenyl)-5-[(phenylamino) carbonyl]-2H-tetrazolium hydroxide) test, using "Cell Proliferation Kit". Even though XTT is a tetrazolium salt, it is decomposed by the dehydrogenase enzyme, which is present in the mitochondria of the metabolically active cells, and it is transformed to formazan, which is soluble in water. The density of the orange color arising from formazan is proportional to the number of living cells. Cell viability is determined by reading the density of the orange color, which has been formed at the end of the incubation period, in a micro plate reader, at $450-475 \mathrm{~nm}$ wavelengths.

At the end of the operation, the concentration that kills half of the healthy cells is set as $\mathrm{IC}_{50}$ value. Sterile 96-wells plates are planted in a way that there is $10 \times 10^{4}$ cells in each plate. Meanwhile, for sterilization purposes polymers were hold under UV light for 4 hours; steril- 
ization was established by holding them in 70\% alcohol for 1 hour and washing with PBS 3 times; afterwards polymers were placed into wells. Following 24 hours of incubation, polymers were removed from wells and XT'T kit was applied.

\section{Cytotoxic Impact of HAI Polymer}

Cytotoxic impact of HAI polymer was evaluated using mouse fibroblast cell line (L929). For sterilization purposes HAI polymer was hold under UV light for 4 hours. Sterilized polymers were placed into $10^{* 4}$ cell planted plates. Cytotoxicity analysis were performed after 24 and 48 hours of incubation, through XTT (2, 3-bis (2-methoxy-4nitro-5-sulfophenyl)-5-[(phenyl amino) carbonyl]$2 \mathrm{H}$-tetrazolium hydroxide). Results were expressed as percent viability.

\section{Polymer (HAl) Doxorubicin Couple}

HAI polymers were hold with the active ingredient of doxorubicin drug in phosphate buffer (PBS) for 5 days, in an incubator at $37^{\circ} \mathrm{C}$. Absorption amounts were calculated through the samples taken from the solution every day. The samples were read in UVVis at $485 \mathrm{~nm}$ wavelengths and it was found that $98 \%$ was absorbed at the end of 5 th day. Dried polymers were placed into PBS solution for release, in an incubator at $37^{\circ} \mathrm{C}$. The release was monitored for 20 days by reading the samples that were taken in predetermined time intervals in UV-Vis at $485 \mathrm{~nm}$. The drug absorption, which has occurred at physiological $\mathrm{pH}$ and body temperature $\left(37^{\circ} \mathrm{C}\right)$, has provided the basic approach for the polymer that contains the active pharmaceutical ingredient to be a bio-material.

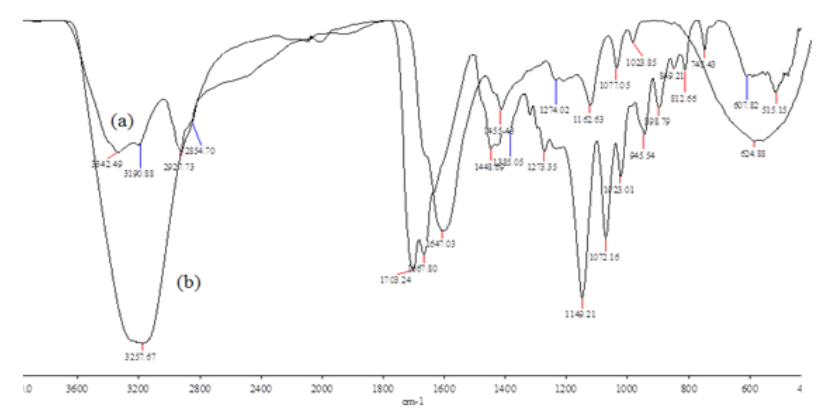

Figure 1: (a)-(b) FTIR analysis of HAI and Doxorubicin adsorbed HAI polymer

\section{RESULTS}

\section{FTIR}

IR spectrum of Poly (HEMA/acrylamide/Itaconic acid) (HAI) polymer is shown in Figure 1a and Figure 1b In Figure 1 (a) the peak belonging to hydroxyl peak of the active ingredient is seen at $3257 \mathrm{~cm}^{-1}$, whereas in Figure 1 (b) it was shifted to $3342-3090$ $\mathrm{cm}^{-1}$ due to HEMA/acrylamide/Itaconic acid polymer. In addition a proton was added to the group because of the binding of the drug active ingredient's to the carbonyl group and alkyl peaks were observed at 2927 and $2854 \mathrm{~cm}^{-1}$. Strong carbonyl peaks observed at $1708-1667 \mathrm{~cm}^{-1}$ in Figure 1 (a) were shifted to $1647 \mathrm{~cm}^{-1}$ at figure 1 (b). Following the binding of the drug, dense C-C peaks were identified around 1448 and $1385 \mathrm{~cm}^{-1}$. Many splits and flourishing were observed on the peaks of the polymer observed around 1162-1023 $\mathrm{cm}^{-1}$ in Figure 1 (a).

Similarly, the peak of the drug observed at 624 cm-1 was seen as two separate peaks in figure 1 (a). According to FTIR analysis, Doxorubicin's active ingredient was bond to the synthesized polymer. ${ }^{7-9}$

\section{Swelling}

This polymer showed $170-175 \%$ swelling at 1000 minutes, in Figure 2. The swelling properties of polymer have been saturated $>200 \%$ at $1600 \mathrm{~min}-$ utes. In the light of these results, it has been concluded that this new polymer is very suitable for the release of Doxorubicin drug. ${ }^{7}$

\section{Adsorption of Doxorubicin's Active Ingredient on HAI Polymer}

The adsorption of doxorubicin's active ingredient on HAI polymer is as given in Figure 3. The adsorp-

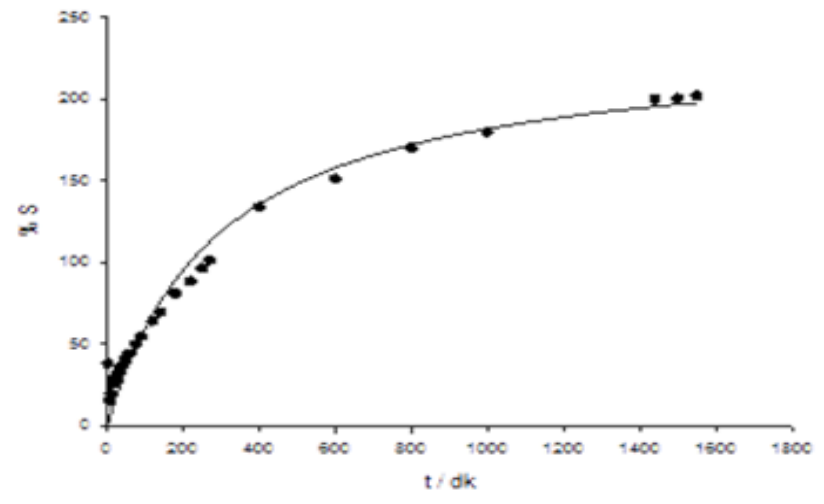

Figure 2: Swelling graph of HAI polymer 


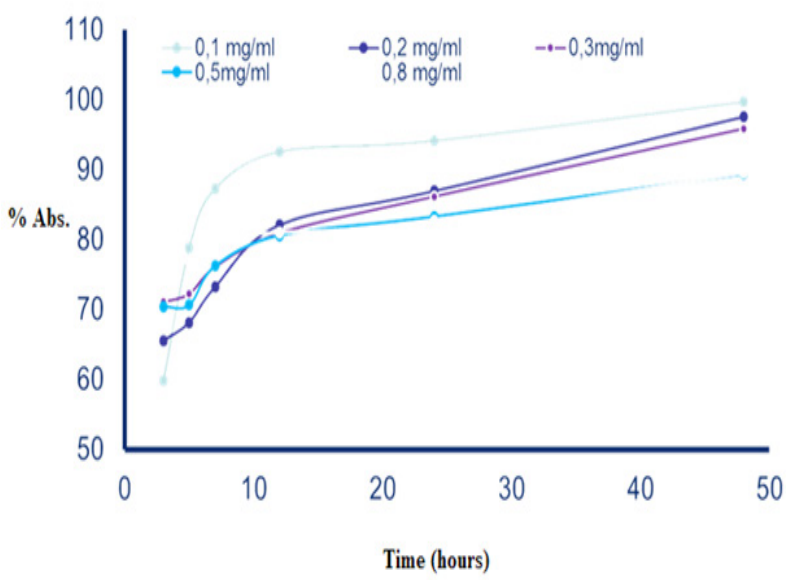

Figure 3: Adsorption Amount of the Polymer over Time in Various Concentrations

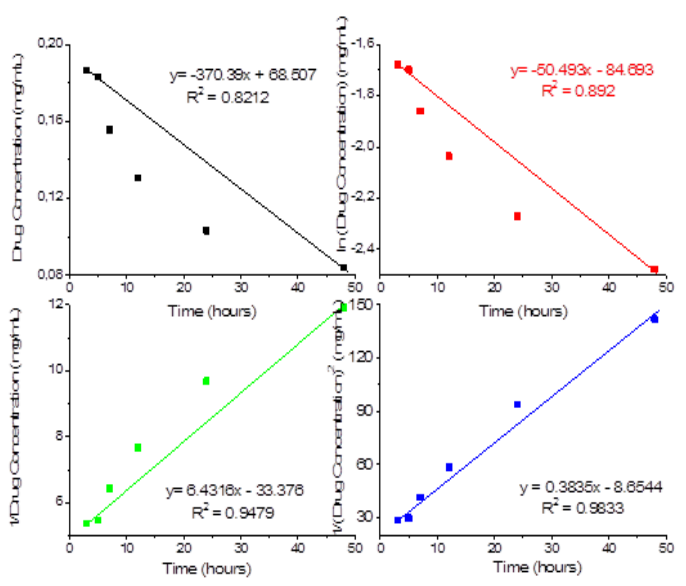

Figure 4: The speed mechanism of the polymer in drug adsorption

tion of the active pharmaceutical ingredient by HAI polymer was examined between $0.1-0.5 \mathrm{mg} / \mathrm{L}$ concentration levels. It has been observed that the adsorption of the polymer decreases as the concentration of the active ingredient increases. It has been found that adsorption amount doesn't significantly increases when the concentration of the active ingredient exceeds $0.2 \mathrm{mg} / \mathrm{L}$. However, it was seen that the increase of the adsorption over time was very high when $0.1 \mathrm{mg} / \mathrm{L}$ active ingredient, which is the lowest value, is added.

At the end of the study, HA-D polymer released $60 \%$ of the active pharmaceutical ingredient.

\section{Adsorption Kinetics}

Many methods can be used to explain the kinetic of a reaction; graphic method is the most practical one.
Graphic method can also be used for adsorption speed equations, in Figure 4.

Therefore, we tried to explain the kinetic by drawing graphs of $0^{\circ}$ (concentration-time), $1^{\circ}$ (ln (concentration)time), $2^{\circ}(1 /$ concentration - time $)$ and $3^{\circ}(1 /($ con-

$$
\begin{aligned}
& -\frac{d[d r u g]}{d t}=k[d r u g]^{3} \\
& \int_{[d r u g]_{0}}^{[d r u g]} d[d r u g]^{3}=-k \int_{0}^{t} d t \\
& \frac{1}{[d r u g]^{2}}=\frac{1}{[d r u g]_{0}^{2}}+k t
\end{aligned}
$$

centration $)^{2}$ - time). These graphs are given in Figure 3. In $0^{\circ}$ mechanism the slope of concentration-time graph is negative; in $1^{\circ}$ mechanism the slope of $\ln$ (concentration)-time graph is also negative; in $2^{\circ}$ mechanism the slope of $1 /$ concentration - time is positive;

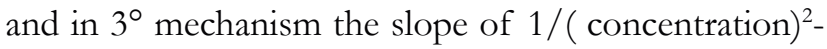
time is also positive. In this case, the graph with the most linear line determines the degree of the mechanism. It can be seen that it has $3^{\text {rd }}$ degree mechanism. ${ }^{7}$

Equities (3), (4) and (5) are the generic expressions derived for a $3^{\text {rd }}$ degree speed mechanism. Here the notations show the followings: [drug]: final concentration of the drug, [drug]: initial concentration of the drug, t: time, $\mathrm{d}[\ldots]$ is a mathematical expression meaning that the term is derivable. As can be seen, equation (5) is similar to a linear equation such as $y=a+b x$ and the equations of the curves that we have shown in Figure 4. Thus, adsorption coefficients of the drug on the polymer may easily be derived from these equations. Accordinglv the initial speed is 8.654 when adsorp-

$$
\Delta G_{a}^{0}=-R T \ln k
$$

tion coefficient is around $38.35 \times 10^{-2}$, half time is 6,651 hours. According to these speed kinetics results, adsorption speed of the drug may be controlled quite regularly through this polymer. ${ }^{5,9}$ According to Eyring's transition state theory, the explicit speed of the mechanism is proportional to the concentration of the activated complex and the frequency of the vibration; thus based on Eyring's equations the free enthalpy of adsorption $\Delta \mathrm{G}^{0}$;

Accordingly, $\Delta \mathrm{G}_{\mathrm{a}}^{0}=2.375 \mathrm{kj} / \mathrm{mol}$.

\section{Cytotoxicity}




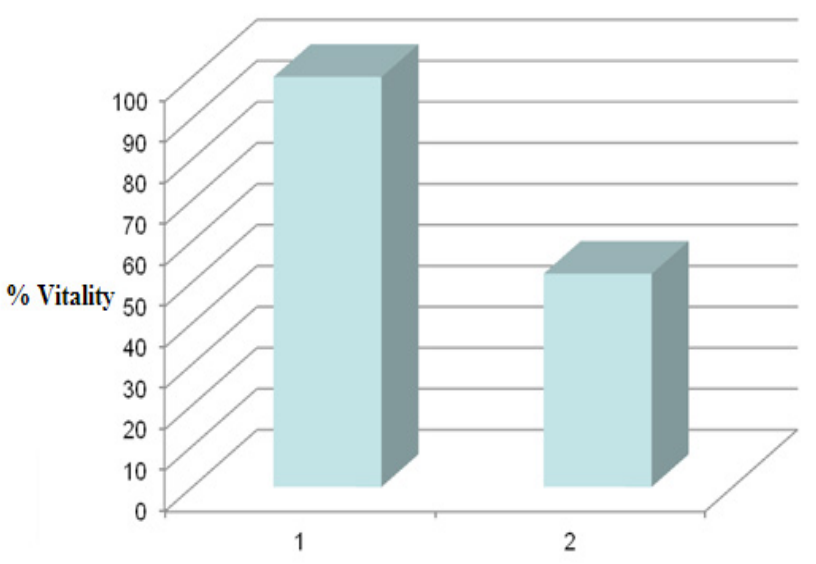

Figure 5: \% Viability of the Polymer (1-Control, 2-HAI,)

As can be seen from Figure 5, the viability ratio of the polymer was $30 \%$ lower than control group. This cytotoxicity impact of the polymer may be due to the lack of polymerization of methacrylate monomers and being imprisoned in the structure of the polymer. In spite of the purification, a certain amount of monomer may stay in the structure. Sorption-based monomers may stay in the holes of the polymers, which are similar to capillary vessels. The problems such as the imprisonment of the excess monomer by being surrounded by the big polymer mass, or the scattering of the monomer inside the polymer may be eliminated through various purification methods, but sorption may be a problem that cannot be solved with such physical methods. It is known in the literature that some monomers have cytotoxic impact. ${ }^{10,11}$ Therefore, cytotoxicity analysis should be performed in drug release studies. HAI polymer that we have synthesized exhibited low toxic impact.

\section{CONCLUSION}

Poly (HEMA/Acrylamide/ Itaconic acid) (HAI) polymers which are soluble in water were prepared by a radical addition reaction. The characterization of the polymer was performed by FTIR analysis. The drug active ingredients to the carbonyl group and alkyl peaks were observed at 2927 and $2854 \mathrm{~cm}^{-1}$ and strong carbonyl peaks observed at $1708-1667 \mathrm{~cm}^{-1}$. We also studied adsorption and kinetics of this polymer. HA-D polymer released $60 \%$ of the active pharmaceutical ingredient. The kinetic study showed that the adsorption mechanism of drug-polymer was $3^{\text {rd }}$ degree speed mechanism. Cytotoxicity test disclosed that this polymer is less toxic than the other polymers. Consequently, it has been concluded that these synthesized polymers are suitable for this active pharmaceutical ingredient.

\section{ACKNOWLEDGEMENT}

None

\section{CONFLICT OF INTEREST}

I can confirm that the manuscript has been read and approved by all named authors and that there are no other persons who satisfied the criteria for authorship but are not listed. I further confirm that the order of authors listed in the manuscript has been approved by all of us.

\section{ABBREVIATIONS USED}

FTIR: Far infrared spectroscopy; HAI: Poly (HEMA/Acrylamide/ Itaconic acid); $\Delta \mathbf{G O}$ a: Free enthalpy of adsorption; [drug]: Final concentration of the drug; [drug]0: Initial concentration of the drug; EGDMA: Ethylene glycol dimetakrilat; APS: Ammoniumpersulphate; TEMED: N,N,N',N'-tetramethylenediamine; XTT: 2, 3-bis (2-methoxy-4-nitro-5-sulfophenyl)-5-[(phenylamino) carbonyl]-2H-tetrazolium hydroxide).

\section{REFERENCES}

1. Fornari FA, Randolph JK, Yalowich JC, Ritke MK, Gewirtz DA. Interference by Doxorubicin with DNA Unwinding in MCF-7 Breast Tumor Cells. Mol. Pharmacol., 1994;45(4):649-56. PMid:8183243.

2. Momparler RL, Karon M, Siegel SE, Avila F. Effect of Adriamycin on DNA, RNA and Protein Synthesis in Cell-Free Systems and Intact Cells. Cancer Res. 1976;36(8):2891-5. PMid:1277199.

3. Frederick CA, Williams LD, Ughetto G, van der Marel GA, van Boom JH, et al. Structural Comparison of Anticancer Drug-DNA Complexes: Adriamycin and Daunomycin. Biochem. 1990;29;2538-49.

4. Pigram WJ, Fuller W, Hamilton LD. Stereochemistry of Intercalation: Interaction of Daunomycin with DNA. Nature New Biol. 1972;235(53);17-9. https://doi.org/10.1038/newbio235017a0; PMid:4502404.

5. Wendel H, De Stanchina E, Fridman J, Malina A, Ray S, Kogan S, et al. Survival signalling by Akt and elF4E in oncogenesis and cancer therapy. Nature. 2004;428(6980);332-7. https://doi.org/10.1038/nature02369; PMid:15029198.

6. Johansson S, Goldenberg D, Griffiths G, Wahren B, Hinkula J. Elimination of HIV-1 infection by treatment with a doxorubicin-conjugated antienvelope antibody, AIDS. 2006;20(15);1911-5. https://doi.org/10.1097/01. aids.0000247111.58961.60; PMid:16988511.

7. Hepokur AI, Hepokur C, Kariper IA. Synthesis and Characterization of Macroporous Poly (Acrylamide-Methacrylic Acid) Cryogel and its Interaction with Clarithromycin, Lat. Am. J. Pharm. 2015;34(9);1842-8

8. Lisa BP, Blanchette JO. Nanoparticles and targated systems for Cancer therapy, Adv. Drug. Deliver. Rev., 2004;22;1649-59

9. Das G, Nicastri A, Coluccio ML, Gentile F, Candeloro P, Cojoc G, Liberale C, De Angelis F, Di Fabrizio E. FT-IR, Raman, RRS measurements and DFT calculation for doxorubicin, Microsc Res Tech. 2010;73(10);991-5. https://doi. org/10.1002/jemt.20849.

10. Jorge, J.H, Giampaolo, E.T., Machado, A.L., Vergani, C.E. 2003. Cytotoxicity of denture base acrylic resins: a literature review. J Prosthet Dent. 90, 190193. https://doi.org/10.1016/S0022-3913(03)00349-4.

11. Weaver RE, Goebel WM. Reactions to acrylic resin dental prostheses. J. Prosthet. Dent. 1980;43(2);138-42. https://doi.org/10.1016/00223913(80)90176-6. 


\section{PICTORIAL ABSTRACT}
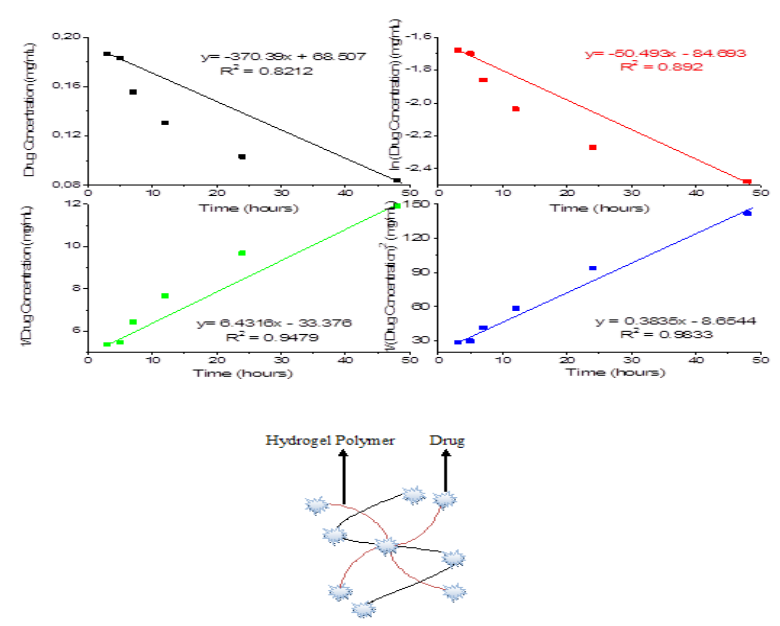

\section{SUMMARY}

- Poly (HEMA/Acrylamide/ Itaconic acid) polymers are suitable for this active pharmaceutical ingredient.

- I hope that this polymer will useful for drug release.

\section{About Author}

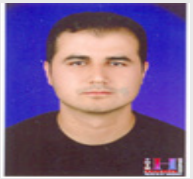

Afșin Kariper: $\mathrm{He}$ is researcher at Erciyes University. He study on physical chemistry in $\mathrm{PhD}$. $\mathrm{He}$ published thin films, material science, drugs, science education articles. He is focused on physical or physical chemistry properties of thin films, material science, drugs and influential factors of their properties. He has been study in Erciyes University.

Cite this article: Kariper IA. The Release of Doxorubicin's Active Ingredient from the Hydrogels with Poly (HEMA/ Acrylamide/ Itaconic acid) and Their Biological Function. Indian J of Pharmaceutical Education and Research. $2017 ; 51(3): 401-6$. 